\title{
Clinical, Bacteriological Profile \& Outcome of Neonatal Sepsis in a Tertiary Care Hospital
}

\author{
Raha BK${ }^{1}$, Baki MA ${ }^{2}$, Begum T ${ }^{3}$, Nahar N ${ }^{4}$, Jahan N, ${ }^{5}$ Begum $\mathrm{M}^{6}$
}

\begin{abstract}
Neonatal sepsis is a major cause of mortality and morbidity in newborn, particularly in developing countries. The spectrum of bacteria which causes neonatal sepsis varies in different parts of the world. The organisms responsible for early onset and late onset sepsis are different. The objective of the study was undertaken to determine the pattern of bacterial isolates responsible for early and late onset neonatal sepsis based on the presence of one or more clinical signs, and its outcome. A cross-sectional prospective study was carried out in the special care baby unit (SCABU) from November 2008 to September 2009 under department of Paediatrics and Neonatology, BIRDEM General Hospital, Dhaka, Bangladesh. Organisms were isolated from $8.9 \%$ of collected blood samples. The male female ratio of culture proven sepsis was 1.7:1. Most of the culture proven septic neonates(71.88\%) were preterm \& $65.63 \%$ had low birth weight. The most frequent clinical presentations of patients with culture-proven sepsis were poor moro reflex (92.2\%), feeding intolerance (90.6\%), jaundice (87.5\%), abdominal distention (76.6\%), and lathergy (73.4\%). The Gram positive and Gram negative bacteria accounted for $6(9.4 \%)$ and 58 $(90.6 \%)$ of the isolates respectively. Around two third of the culture-proven septic neonates $(70.3 \%)$ presented with early onset sepsis, while $29.7 \%$ presented with late onset sepsis. Klebsiella pneumoniae was the most common pathogen both in early onset (31.25\%) and late onset (6.25\%) sepsis. Serratia (18.75\%) was the second most common pathogen in early onset sepsis. Total mortality rate was $9.38 \%$. Preterm, low birth weight and Gram negative sepsis contributes majority of mortality. Gram negative organism especially Klebsiella pneumoniae contributed highest in early onset sepsis and neonatal death (6.25\%) due to sepsis.
\end{abstract}

1. Corresponding Author : Dr. Biplob Kumar Raha MBBS, FCPS (Paediatrics)

Assistant Professor, Department of Neonatology Ad-din Medical College Hospital, Dhaka, Bangladesh E. mail: biplob_raha@yahoo.com

2. Dr. Md. Abdul Baki, MBBS, MD (Neonatology) Registrar, Department of Paediatrics and Neonatology BIRDEM General Hospital-2, Dhaka, Bangladesh

3. Professor Tahmina Begum, MBBS, FCPS, MD, MMED (UK) Professor and Head, Department of Paediatrics and Neonatology BIRDEM General Hospital-2, Dhaka, Bangaldesh

4. Professor Nazmun Nahar, MBBS, FCPS, FRCP Professor, Department of Paediatrics and Neonatology BIRDEM General Hospital, Dhaka, Bangladesh

5. Dr. Nasim Jahan, MBBS, FCPS (Paediatrics) Assistant Professor, Department of Neonatology Ad-din Medical College Hospital, Dhaka, Bangladesh

6. Dr. Marium Begum, MBBS, MD (Paediatrics), DCH Assistant Professor, Department of Neonatology Ad-din Medical College Hospital, Dhaka, Bangladesh.

\section{Keywords}

Bacteriological profile, Gram negative bacteria, Neonatal sepsis, Special care baby unit(SCABU)

\section{Introduction}

Neonatal sepsis is a clinical syndrome characterized by systemic signs of circulatory compromise caused by invasion of the blood stream by bacteria in the first four weeks of life ${ }^{1}$, and is more common in developing countries compared with developed countries ${ }^{2}$. Neonatal mortality rate (NMR) is 27/1000 live birth ${ }^{3}$ and Neonatal sepsis contributes $36 \%$ of total death in Bangladesh ${ }^{4}$. Neonatal sepsis has been classified as either early onset sepsis (EOS) (0-7 day of age) or late onset sepsis (LOS) (7-28 days of age) ${ }^{2,5}$. EOS is due to vertical transmission during labor or birth. It includes bacteremia and/or sepsis, meningitis and pneumonia. LOS is due to vertical, horizontal or nosocomial infection. Its most clinical manifestations are: meningitis (30-40\%), bacteremia (40\%), septic arthritis (510\%), and rarely omphalitis and osteomyelitis. The reported incidence of neonatal sepsis varies from 7 to 38 per 1000 live birth in Asia $^{6}$. In most developing countries, gram-negative bacteria remain the major cause of neonatal sepsis ${ }^{7,8}$. These organisms have developed increased drug resistance over the last two decades ${ }^{9}$. On the other hand Group B Streptococcus (GBS) has been the most frequent etiological agent of neonatal sepsis in developed countries, being responsible for high morbidity and mortality ${ }^{10}$. Since the spectrum of organisms that cause neonatal sepsis changes overtime and varies from region to region and hospital to hospital even in the same city/country, it is necessary to conduct periodic surveillance to access the changing pattern of organisms causing neonatal sepsis. Therefore knowledge of the pattern of bacterial isolates and their antimicrobial susceptibility pattern is useful for prompt treatment of patients. Although an extensive research is available worldwide ${ }^{2,9,11}$ very few reports are available on neonatal sepsis in Bangladesh. Considering this, the present study was undertaken to highlight the pattern of bacterial isolates responsible for early onset and late onset neonatal sepsis based on the presence of one or more clinical signs, and its outcome.

\section{Materials \& Methods}

A cross-sectional prospective study over a period of November 2008 to September 2009, a total of 720 neonates (0 to 28 days of age) with suspected clinical diagnosis of septicemia admitted to special care baby unit (SCABU) under department of Paediatrics and Neonatology, BIRDEM General Hospital were investigated with the aim to detect bacterial pathogens responsible for early and late onset neonatal sepsis based on the presence of one or more clinical signs, and its outcome. Neonates were suspected having sepsis if they presented with one of the following signs or symptoms: fever (temperature $>38^{\circ} \mathrm{C}$ ), Hypothermia (Temperature $<36^{\circ} \mathrm{C}$ ), decreased sucking, poor sucking 
or not sucking, lethargy, irritability, seizure, apnea, cough, respiratory distress, abdominal distention, poor moro reflex etc. Risk factors in the mother included prolonged rupture of membranes (PROM) of $>12$ hours, maternal fever during delivery, Prolonged labour, urinary tract infection, chorioamnionitis and meconium stained amniotic fluid. Both premature and full terms were included and all must have a positive blood culture. Neonates who had clinical picture of sepsis without positive blood culture were excluded. Written informed consents were obtained from the parents/guardians, and were investigated for bacterial etiologic agents. Demographic, clinical and other relevant data were obtained by attending pediatrician $/ \mathrm{s}$ and were transferred to the questionnaire prepared for this study. Target neonates were divided into two groups according to the timing of clinical signs as early onset (clinical signs of sepsis from birth to 7 days old) and late onset (clinical signs of sepsis from 8 to 28 days old) infections. Neonates were also classified into normal birth weight (birth weight $>2500 \mathrm{gm}$ ) or low birth weight (birth weight $<2500 \mathrm{gm}$ ). According to gestational age they were again divided into term (gestational age $>37$ weeks) and preterm (gestational age $<37$ weeks) baby. Blood culture, chest X-ray and laboratory tests including complete blood count (CBC), blood sugar (BS) and S.electrolytes were performed for all patients. Using aseptic technique by applying Povidone iodine and $70 \%$ alcohol at the site of veinpuncture, $2 \mathrm{ml}$ venous blood was drawn from the peripheral vein by the attending nurse and then the blood was inoculated into a blood culture bottle containing Tryptone Soy Broth (TSB) and Brain Heart infusion Broth. The specimens were transported immediately to microbiological laboratory and incubated for one week in $37^{\circ} \mathrm{C}$ and were daily checked for evidence of bacterial growth. For positive broth cultures, subcultures were made on solid media (Blood agar and McConkey agar) and were incubated in $37^{\circ} \mathrm{C}$ for 24 to 48 hours. The grown bacteria were identified by colony morphology, gram stain and biochemical tests. Antimicrobial susceptibility testing was performed for all blood culture isolates according to the criteria of the National Committee for Clinical Laboratory Standards by disk diffusion method. Data analysis was done using statistical package for social sciences (SPSS) software version 12.0.

\section{Results}

During the study period 720 samples were collected from the neonates admitted in the NICU. Among them Positive blood cultures were obtained for 64 neonates $(8.9 \%)$. Of these, $46(71.88 \%)$ were preterm and $18(28.13 \%)$ were term, $42(65.63 \%)$ neonates were with low birth weight and 22 newborns $(34.38 \%)$ with normal birth weight (Table-1, $2)$. There were $40(62.5 \%)$ male and $24(37.5 \%)$ female, with the male to female ratio of 1.7:1 (Table-1). The commonest risk factors were $29.69 \%(19 / 64)$ mother had ruptured membranes for more than 12 hours, prolonged labour was present in $15.63 \%(10 / 64)$, and maternal fever during delivery was present in $7.81 \%(5 / 64)$. The most frequent clinical presentations were poor moro reflex $(92.2 \%)$, feeding intolerance $(90.6 \%)$, jaundice $(87.5 \%)$, abdominal distention (76.6\%), and lathergy (73.4\%) (Table-3). Fifty eight (90.6\%) had sepsis with Gram negative bacteria and 6(9.4\%) with Gram positive bacteria (Table-4). Ratio of Gram negative organisms $(90.6 \%)$ to Gram positive organisms (9.4\%) was 9.6:1. The most common isolated Gram negative bacteria were Klebsiella pneumonia $(37.5 \%)$, Serratia $(25 \%)$, Pseudomonas aeruginosa (10.9\%), Citrobacter (10.9\%) and Acinetobacter (6.3\%) (Table-4). Staphylococcus aureus were the most isolated prevalent Gram positive bacteria $(6.3 \%)$ (Table-4). Among neonates with sepsis, 45 patients (70.3\%) had early onset and $19(29.7 \%)$ had late-onset neonatal sepsis $($ Table-1,4). Klebsiella pneumonia $(37.5 \%)$ was the most common pathogen in both early-onset $(31.25 \%)$ and late-onset $(6.25 \%)$ sepsis. Serratia $(25 \%)$ was the second most common organism and was more common in early onset $(18.75 \%)$ neonatal sepsis. Death was low in this study $6(9.38 \%)$. Klebsiella pneumonia contributes majority of death $4(6.25 \%)$ (Table-4).

Table- 1: Distribution of culture proven septic neonates according to onset of sepsis, gestational age, birth weight, sex, and mortality

\begin{tabular}{|c|c|c|c|c|c|c|c|c|}
\hline \multirow[t]{2}{*}{ Category } & \multirow[t]{2}{*}{$\begin{array}{c}\text { Total number } \\
\text { of cases }\end{array}$} & \multicolumn{2}{|c|}{ GA (wks) } & \multicolumn{2}{|c|}{ Wt (gm) } & \multirow[t]{2}{*}{ Male } & \multirow[t]{2}{*}{ Female } & \multirow[t]{2}{*}{ Mortality } \\
\hline & & $\begin{array}{l}\text { Term } \\
>\mathbf{3 7}\end{array}$ & $\begin{array}{c}\text { Preterm } \\
<\mathbf{3 7}\end{array}$ & $\begin{array}{c}\text { AGA } \\
>2500\end{array}$ & $\begin{array}{l}\text { LBW } \\
<2500\end{array}$ & & & \\
\hline Early onset & $45(70.3)$ & $11(17.19)$ & $33(51.56)$ & $14(21.88)$ & $32(50)$ & $33(51.56)$ & $16(25)$ & $6(9.38)$ \\
\hline Late onset & $19(29.7)$ & $7(10.94)$ & $13(18.75)$ & $8(12.5)$ & $10(15.63)$ & $7(10.94)$ & $8(12.5)$ & 0 \\
\hline Total & 64(100) & $18(28.13)$ & 46 (71.88) & $22(34.38)$ & $42(65.63)$ & $40(62.5)$ & $24(37.5)$ & $6(9.38)$ \\
\hline
\end{tabular}

Table- 2: Characteristics of gestational age and birth weight in neonatal sepsis according to causative organism

\begin{tabular}{|c|c|c|c|c|c|c|c|c|}
\hline Features & $\begin{array}{c}\text { K. } \\
\text { pneumoniae }\end{array}$ & Serratia & $\begin{array}{c}\text { Pseudomonas } \\
\text { aeruginosa }\end{array}$ & Citrobacter & Acinetobacter & $\begin{array}{c}\text { S. } \\
\text { aureus }\end{array}$ & Enterococci & Total \\
\hline \multicolumn{9}{|l|}{ Gestational age } \\
\hline Term & $6(9.38)$ & $2(3.13)$ & 0 & $2(3.13)$ & $2(3.13)$ & $4(6.25)$ & $2(3.13)$ & $18(28.13)$ \\
\hline Preterm & $18(28.13)$ & $14(21.88)$ & $7(10.94)$ & $5(7.81)$ & $2(3.13)$ & 0 & 0 & $46(71.88)$ \\
\hline \multicolumn{9}{|l|}{ Birth weight } \\
\hline $\operatorname{AGA}(>2500 \mathrm{gm})$ & $8(12.5)$ & $4(6.25)$ & 0 & $2(3.13)$ & $2(3.13)$ & $4(6.25)$ & $2(3.13)$ & $22(34.38)$ \\
\hline LBW $(<2500$ gm $)$ & $16(25)$ & $12(18.75)$ & $7(10.94)$ & $5(7.81)$ & $2(3.13)$ & 0 & 0 & $42(65.63)$ \\
\hline
\end{tabular}


Table-3: Common clinical manifestations of culture proven neonatal sepsis

\begin{tabular}{lccc}
\hline \multicolumn{1}{c}{ Clinical features } & \multicolumn{3}{c}{ Number of features $(\%)$} \\
& All & Early onset & Late onset \\
\hline Poor Moro reflex & $59(92.2)$ & $44(68.8)$ & $15(23.4)$ \\
Feeding intolerance & $58(90.6)$ & $37(57.8)$ & $21(32.8)$ \\
Jaundice & $56(87.5)$ & $31(48.4)$ & $25(39.1)$ \\
Abdominal Distention & $49(76.6)$ & $34(53.1)$ & $15(23.4)$ \\
Lathergy & $47(73.4)$ & $32(50)$ & $15(23.4)$ \\
Pallor & $34(53.1)$ & $14(21.9)$ & $20(31.3)$ \\
Fever & $30(46.9)$ & $18(28.1)$ & $12(18.8)$ \\
Respiratory Distress & $25(39.1)$ & $17(26.6)$ & $8(12.5)$ \\
Apnoea & $20(31.3)$ & $13(20.3)$ & $7(10.9)$ \\
Cyanosis & $11(17.2)$ & $9(14.1)$ & $2(3.1)$ \\
Convulsion & $11(17.2)$ & $6(9.4)$ & $5(7.8)$ \\
Hypothermia & $8(12.5)$ & $5(7.8)$ & $3(4.7)$ \\
\hline
\end{tabular}

Table-4: Type and number of bacterial isolates in neonates with sepsis based on the sepsis onset \& mortality

\begin{tabular}{lllll}
\hline Microorganism & \multicolumn{2}{c}{ Type of sepsis } & Total(\%) & death (\%) \\
& Early onset (\%) & Late-onset (\%) & \\
\hline Klebsiella pneumoniae & $20(31.25)$ & $4(6.25)$ & $24(37.5)$ & $4(6.25)$ \\
Serratia & $12(18.75)$ & $4(6.25)$ & $16(25)$ & $1(1.56)$ \\
Pseudomonas aeruginosa & $4(6.25)$ & $3(4.69)$ & $7(10.93)$ & $1(1.56)$ \\
Citrobacter & $6(9.38)$ & $1(1.56)$ & $7(10.93)$ & \\
Acinetobacter & $3(4.69)$ & $1(1.56)$ & $4(6.25)$ & $4(6.25)$ \\
Staphylococcus aureus & 0 & $4(6.25)$ & $2(3.13)$ & $\mathbf{6 ( 9 . 3 8 )}$ \\
Enterococci & 0 & $2(3.13)$ & $\mathbf{6 4 ( 1 0 0 )}$ & \\
Total & $\mathbf{4 5 ( 7 0 . 3 )}$ & $\mathbf{1 9 ( 2 9 . 7 )}$ & &
\end{tabular}

\section{Discussion}

In this study, prevalence of documented neonatal sepsis with positive culture was $8.9 \%$. The isolation rate of bacteria in this study is comparable to rates reported in Bangladesh $(9 \%)^{12}$, Iran $(6.6 \%)^{13}$, Libya $(5.9 \%)^{14}$, Bahrain $(4.2 \%)^{15}$. Higher isolation rates were reported in Nigeria $(45.9 \%)^{16}$, India $(52.6 \%)^{17}$,Pakistan $(54.0 \%)^{18}$, and Bangladesh $(20 \%)^{19}$. In the present study, $70.3 \%$ and $29.7 \%$ neonates presented with early onset sepsis and late onset sepsis respectively, which is in agreement with the reports from other developing countries e.g. in Iran $(77.5 \% \text { vs. } 22.5 \%)^{13}$ and in a study of Bangladesh $(70.7 \% \text { vs. } 29.3 \%)^{20}$, but in contrast with reports from Bangladesh $(40 \% \text { vs. } 60 \%)^{21}$,Saudi Arabia $(39 \% \text { vs.61\%) })^{22}$, Pakistan $(42 \% \text { vs. } 58 \%)^{18}$ and Libya (31 vs. $69 \%)^{14}$, where late onset sepsis is more common. The possible explanation for a higher frequency of EOS in this study might be the more referral of preterm labors to our center. This study has shown male female ratio of 1.7:1 which is similar to another report ${ }^{23}$.

In this study, Ratio of Gram negative organisms to Gram positive organisms were $9.6: 1$ which is similar to that of other studies which showed that Gram negative bacteria were responsible for most cases of neonatal sepsis $13,18,21,24,25$. Although some other studies found that Gram positive bacteria were the commonest cause of neonatal sepsis ${ }^{7,26,27}$, while one study showed that the frequency of isolation of both Gram positive and Gram negatives was equal ${ }^{22}$.
Among Gram negatives organisms, most cases were due to Klebsiella pneumoniae and serratia and commonest gram positive organisms was Staphylococcus aureus (s. aureus). Klebsiella pneumoniae was the predominant organism for both early onset and late onset sepsis. Serratia was the second most common organism isolated in this study. Klebsiella pneumoniae is emerging as a common bacteria in hospital settings ${ }^{12,21,28}$ But the pattern of isolated organisms in our study slightly differs from the findings in a study in $\operatorname{Iran}^{13}$ and India ${ }^{17}$ where Pseudomonas aeruginosa was the most common cause of neonatal sepsis followed by Klebsiella pneumoniae and Escherichia coli(E. coli). In similar studies from Bangladesh, Nepal and Pakistan, E. coli was the leading cause of neonatal sepsis followed by Klebsiella pneumoniae 17,21 . In other studies gram positive bacteria such as S. aureus and Group B streptococcus (GBS) were found to be the most common isolates in neonatal septicemia ${ }^{26}$. Studies from different countries report Coagulase negative staphylococci (CONS) as the predominant organisms in $\operatorname{LOS}^{27,29}$. Prior to antibiotic era, the mortality from septicemia was more than $90 \%$. In the present time mortality remains high, between $20 \%-40 \%{ }^{4}$. The mortality rate in this study was low $(9.38 \%)$ which may be due to presence of adequate supportive facilities in the study hospital, since this is a tertiary care hospital and NICU provide level 3 care and other logistic support. Most of the death occurred in this study were preterm, low birth weight and early onset sepsis. Klebsiella pneumoniae was the main organism causing mortality. 
Klebsiella pneumonia, Serratia, Pseudomonas aeruginosa, Staphylococcus aureus were the most common organisms causing neonatal sepsis. Klebsiella pneumonia was more common in both early and late onset sepsis. Serratia was significantly more common in early onset than in late onset sepsis. There was significant correlation between mortality rate and type of causative pathogen, gestational age, birth weight, onset of sepsis in this study. Different neonatal intensive care unit (NICU) show different epidemiological data for neonatal sepsis. So collection of up-to-date \& site specific data is mandatory for appropriate use of antibiotics.

\section{References}

1. Edmond K, Zaidi A. New approaches to preventing, diagnosing and treating neonatal sepsis. PLOS Med 2010;7(3):e1000213.

2. Vergnano S, Sharland M, Kazembe P, Wansambo CM, Heath PT. Neonatal sepsis : an ernational perspective. Arch. Dis.Child.Fetal Neonatal 2005;90:220-24.

3. UNICEF. The State of World's Children 2012;87 -107.

4. National institute of population research and training (NIPORT), Mitra and associates, and ORC macro, Bangladesh Demographic and Health survey 2004. Dhaka Bangladesh and Calverton, Mayland [USA]: National institute of population research and training , Mitra and associates, and ORC macro;2005.

5. Kaftan H, Kinney JS (1998). Early onset neonatal bacterial infections. Semin Perinatol 1998;22:15-24.

6. Lim NL, Wong YH, Boo NY, Kasim MS, Chor CY. Bacteraemic infections in a neonatal intensive care unit: a nine months survey. Med J Malaysia 1995;50:59 -63.

7. Anwer SK, Mustafa S, Pariyani S, Ashraf S, Taufiq KM. Neonatal sepsis: an etiologic study. J Pak Med Assoc 2000;50:91-94.

8. Joshi SG, Ghole VS, Niphadkar KB. Neonatal gram negative bacteremia. Indian J Pediatr 2000;67:27-32 .

9. Bhutta ZA. Neonatal bacterial infections in developing countries: strategies for prevention. Semin Neonatol1999;4:159-71.

10. Freedman RM, Ingram DL, Gross I, Ehrenkranz RA, Warshaw JB, Baltimore RS. A half century of neonatal sepsis at Yale. Am J Dis Child 1981;135:140-44.

11. Klein JO. From harmless commensal to invasive pathogen coagulase-negative staphylococci. N Engl J Med 1990;323:339-40.

12. Hossain MM, Afroza S, Shirin M, Chowdhury NA, Saha SK. Bacterial aetiology of neonatal sepsis in a tertiary care hospital in Bangladesh. Bangladesh J Child Health 2004;28:81-85.

13. Movahedian AH, Moniri R, Mosayebi Z. Bacterial Culture of Neonatal Sepsis. Iranian J Publ Health 2006;35:84-89.

14. Misallati A, el-Bargathy S, Shembesh N. Blood-cultureproven neonatal septicaemia: a review of 36 cases. East Mediterr Health J. 2000; 6: 483-6.
15. Bindayna KM, Jamsheer A, Farid E, Botta GA. Neonatal sepsis1991-2001: prevalent bacterial agents and antimicrobial susceptibilities in Bahrain. Med Princ Pract 2006;15:131-6.

16. Meremikwu MM, Nwachukwu CE, Asuquo AE, Okebe JU, Utsalo SJ. Bacterial isolates from blood cultures of children with suspected septicaemia in Calabar, Nigeria. BMC Infectious Disease 2005;5:110-17.

17. Murty DS, Gyaneshwari M. Blood cultures in pediatric patients: a study of clinical impact. Indian J Med Microbiol 2007;25:220-4.

18. Aftab R, IqbalI. Bacteriological agents of neonatal sepsis in NICU at Nishtar Hospital Multan. J Coll Physicians Surg Pak 2006;16:216-9.

19. MF Haque, SM Safiquzzaman, AFM Salim, F Monzur, SH Banu. Bacteriological profile of neonatal septicemia in a neonatal unit (SCANU). DS (Child) H J 2008;24:48 .

20. Rasul CH, Hassan MA, Habibullah M. Neonatal sepsis and use of antibiotic in tertiary care hospital. Pak J Med Sci 2007;23:78-81.

21. Ahmed AS, Chowdhury MA, Hoque M, Darmstadt GL. Clinical and bacteriological profile of neonatal septicemia in a tertiary level pediatric hospital in Bangladesh. Indian Pediatr2002;39:1034-9.

22. Umran K, Twum-Danso K. A case control study of neonatal sepsis: Experience from Saudi Arabia. J Trop Pediatr 1997;43:84-8.

23. Jain NK, Jain VM, Maheshwari S. Clinical profile of neonatal sepsis. Kathmandu Univ Med J 2003;1:117-20.

24. Ganatra HA, Stoll BJ, Zaidi AKM. International perspective on early -onset neonatal sepsis. Clin Perinatol 2010;37:501-23.

25. Rahman S, Hameed A, Roghani MT, Ullah Z. Multidrug resistant neonatal sepsis in Peshawar, Pakistan. Arch Dis Child Fetal Neonatal 2002;87:52-54.

26. Robillard PY, Nabeth P, Hulsey TC, Sergent MP, Périanin J, Janky E. Neonatal bacterial septicaemia in a tropical area. Four-year experiences in Guadeloupe (French West Indies). Acta Paediatr 1993;82:687 -9.

27. Munson DP, Thompson TR, Johnson DE, Rhame FS, VanDrunen N, Ferrieri P. Coagulase-negative staphylococcal septicemia: experience in a newborn intensive care unit. J Pediatr 1982;101:602-5.

28. Mannan MA, Shahidullah M, Noor MK, Dey AC, Nasrin $\mathrm{N}$, Marma U. Nosocomial infections in a newborn intensive care unit of a tertiary care health. Bangladesh J Child Health 2008;32:92-96.

29. Baumgart S, Hall SE, Campos JM, Polin RA. Sepsis with coagulase-negative staphylococci in critically ill newborns. Am J Dis Child 1983;137:461. 